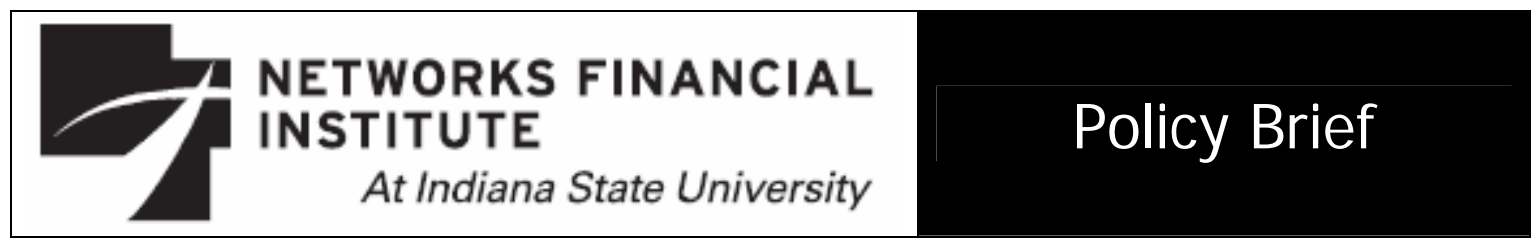

2008-PB-03

February 2008

\title{
State Regulation and Consumer Protection in the Insurance Industry \\ Sharon Tennyson
}

Abstract: In the recent debate over the appropriate governmental level at which to regulate insurance markets, opponents of a new federal role often raise concerns about the adequacy of consumer protection if regulation is removed from the states. This paper analyzes the need for market conduct regulation in insurance markets, and the arguments for state versus federal provision of this type of regulation. The paper then examines the provision of consumer protection regulation by the states in light of proposals for an increased federal role in insurance regulation.

About the Author: Sharon Tennyson is Associate Professor in the Department of Policy Analysis and Management at Cornell University. Dr. Tennyson is a noted expert on economic and policy issues related to insurance, and has published extensively on topics related to government regulation of insurance markets, insurance fraud, insurance distribution and consumer attitudes and knowledge of insurance. Her research has received funding from a variety of sources including the National Science Foundation, and has been published in high quality economics, insurance and finance journals and in prestigious edited collections. Dr. Tennyson is a member of several national organizations and editorial boards, and is a past president of the Risk Theory Society. She holds a Ph.D. in economics from Northwestern University, and was previously on the faculty of the Wharton School of the University of Pennsylvania.

Keywords: Insurance regulation, federalism, consumer complaints.

J EL Codes: G22, L51, H77.

The views expressed are those of the individual author and do not necessarily reflect official positions of Networks Financial Institute. Please address questions regarding content to Sharon Tennyson at st96@cornell.edu. Any errors or omissions are the responsibility of the author. Valuable research assistance was provided by Hani Singer and Anna Oh.

NFI working papers and other publications are available on NFI's website (www.networksfinancialinstitute.org). Click "Research" and then "Publications/Papers." 


\section{State Regulation and Consumer Protection in the I nsurance I ndustry Sharon Tennyson}

\section{Introduction}

Virtually all insurance regulation in the U.S. is undertaken by the individual state governments, an unusual arrangement that arises out of judicial decisions in the 1800s that were codified by the McCarran Ferguson Act of 1945. The federal role in insurance markets is limited to involvement enabled by individual laws that address specific types of insurance, insurance arrangements or insuring institutions; or that require states to undertake certain actions in insurance markets in which there is a federal role.

This system of state insurance regulation has come under increasing pressure from the U.S. Congress and from certain segments of the insurance industry. ${ }^{1}$ Criticisms of state regulation have included charges of regulatory inadequacy and quality, burdensome and wasteful duplication of efforts by the states, politicized or outmoded rate and form regulations, or misplaced regulatory emphasis. The perceived shortcomings of state regulation have led to demands for some federal role in insurance regulation, and the introduction in Congress of bills to allow for optional federal chartering (OFC) of insurance companies (Harrington, 2006). An OFC would create a dual regulatory system in which insurers could choose a federal charter subject to federal regulation, or a state charter subject to state regulation.

Aside from considerations of costs associated with changing the system and the inability to predict with certainty the actions of a federal regulator, the main arguments for and against federal regulation have centered on the comparative strengths and

\footnotetext{
${ }^{1}$ This is especially true since the 1999 passage of the Gramm-Leach-Bliley Act, which removed prohibitions on joint ownership of financial services firms, thereby expanding the scope of competition in industry.
} 
weaknesses of centralized versus decentralized regulation. Advocates of a federal role note that an important potential benefit is the efficiency gains associated with eliminating duplicative regulatory efforts and reducing the compliance costs of insurers who operate in more than one state. With regard to the OFC specifically, advocates argue that regulatory competition between states and the federal government will lead to the most efficient regulation. Opponents of a federal role argue that the states are better able to provide consumer protection regulation, and that consumers will be harmed under federal regulation. Some also raise concerns that regulatory competition will increase the industry’s influence over regulators, reducing consumer protections at all levels of government (Hunter, 2003).

One reason that consumer protection issues come to the fore in this debate is that the state insurance departments currently receive large numbers of contacts from individual insurance consumers. Each year the state insurance regulators collectively field several million consumer inquiries and several hundred thousand consumer complaints. Proponents of state regulation have questioned whether a federal regulator would be willing or able to maintain this high level of service to consumers.

This paper examines the provision of consumer protection regulation by the states in light of proposals for an increased federal role in insurance regulation. I analyze whether state efforts appear to have declined over time in response to pressure for a federal role in regulation. I also consider whether an increased federal role may lead to reduced consumer protections, by comparing insurance regulation to federal and state bank regulation. Before turning to these questions I analyze the need for consumer 
protection regulation in insurance markets, and I examine in more detail the arguments

for state versus federal provision of this type of regulation.

\section{Consumer Protection in Insurance Markets}

The primary motivation for market conduct regulation in insurance markets is the idea that consumers are imperfectly informed about products, prices and seller quality, and that there are significant impediments to their becoming informed. ${ }^{2}$ A central information problem that insurance consumers face is judging product quality. The quality characteristics of an insurance policy are difficult to ascertain due to the complexity of the contract, the contingent nature of many of the services provided (e.g., claims handling and payments) and the fact that services may be provided over time (e.g., investments). As a result, product quality is difficult to ascertain prior to purchase and may remain so even after significant experience with the product. Price comparisons can also be difficult, since prices vary with risk characteristics of the buyer. Finally, product heterogeneity across sellers may be manifested in details regarding insured events or coverage for specific events, making comparisons of price and quality dimensions of products even more difficult. These features of insurance contracts increase the potential for seller misrepresentation or consumer misunderstanding in insurance transactions.

Counterbalancing these problems are competitive market forces which should work to protect consumers. Firms engaged in competition have strong incentives to maintain faith in their products and thus to provide high quality products at appropriate prices. This is especially true in markets for financial products, in which consumer confidence is central to the existence of the market and quality concerns will reduce demand throughout the industry. Such reputation constraints on quality will work only

\footnotetext{
${ }^{2}$ See Tennyson (1999) for further discussion.
} 
imperfectly, however, because each individual seller will incorrectly weigh the costs of misrepresentation or low quality provision - taking into account only the benefits and costs to him or her and not those for the industry as a whole. This is because industry reputation is a public good which benefits all sellers irrespective of their contribution to its maintenance.

The importance of consumer confidence and the public goods aspects of industry reputation create the case for industry self-regulation or government regulation of market conduct. Government regulation can be either a substitute or a complement for selfregulation, but it provides stronger enforcement powers than those available to selfregulatory bodies. Enforcement powers provide government regulators with considerable discretion regarding the scope and form of market conduct regulations, and a variety of approaches are employed.

Regulatory tools that focus on ex-ante proscription and prevention include prior approval of products and forms, restrictions on specific behaviors, and mandating disclosure of certain types of information. Ex-post approaches that focus on monitoring and remedies include market conduct examinations, compliance examinations and tracking and investigation of consumer complaints. Ex-post approaches to regulation may be complements to ex-ante approaches when they serve to enforce compliance with rules, but may be substitutes for ex-ante approaches when they serve to identify and remedy problems.

State insurance regulators use a combination of ex-ante and ex-post approaches to market conduct regulation but rely on a different mix of tools than regulators of other financial services. In ex-ante regulation, insurance regulators rely more heavily on prior 
approval and behavioral restrictions, whereas disclosure requirements tend to be the norm in other financial services. With regard to ex-post market conduct regulation insurance, regulators tend to engage in fewer and less intensive examinations but handle far more consumer complaints than bank regulators (Bair, 2003).

\section{State versus Federal Provision}

Among the key economic arguments of those who advocate a greater federal role in insurance regulation are the potential efficiency gains from centralizing regulation. In general, economic efficiency favors decentralization to allow regulation to be tailored to local conditions and preferences. However, efficiency also requires that regulation be provided by a government which is large enough to internalize all of the costs and benefits of regulation (Oates, 1972). ${ }^{3}$

Centralized regulation may be necessary to capture economies of scale and to provide regulation at the lowest possible cost. Centralized regulation can eliminate duplication of regulatory costs and reduce the compliance costs of insurers who operate in many states. Centralization may also be needed if there are significant spillovers of regulatory costs or benefits between jurisdictions. If there are spillovers of regulatory benefits beyond state borders, this can lead to too little regulation since states may freeride on regulation provided by the other states. Grace and Phillips (2007) suggest that such free-riding occurs in state insurance solvency regulation. On the other hand if the costs of regulation extend beyond the state, each state has an incentive to regulate too much due to the ability to export costs to others. Harrington (1992) suggests that such cost-exporting allows states to engage in overly restrictive rate regulation.

\footnotetext{
${ }^{3}$ Besley and Coate (2003) note that this argument rests on the assumption that the federal government must provide a uniform level of the good or service to each jurisdiction. This seems a reasonable assumption in the case of regulation.
} 
These arguments suggest that regulation which involves standardized interventions - such as prior approval of forms and company examinations - may be candidates for greater centralization. ${ }^{4}$ Interestingly, the states and the National Association of Insurance Commissioners (NAIC) have undertaken steps to move in that direction. Progress toward interstate compact agreements, multi-state examinations, and other regulatory modernization efforts to reduce duplication and compliance costs has been made in recent years. ${ }^{5}$

If the need for regulation differs across states, economic theory predicts that decentralized provision may be preferable. Decentralization allows for the greatest responsiveness of regulation to jurisdictional differences in the demand for quantity and quality of regulation. Problems that are specific to a single jurisdiction will be more apparent to a local authority, and it may be less costly for a local regulator to obtain information on local needs and problems. Moreover, in dealing with problems unique to a single jurisdiction, economies of scale are less likely to be important and regulatory spillovers to other jurisdictions are less likely.

These arguments suggest that state regulation is favored when dealing with issues that may vary considerably across states. Disciplinary actions and disaster management are examples of these functions, since they are dealt with via response systems rather than through rule making or examinations. One area in which such differences might be particularly relevant is in responding to the complaints of individual consumers regarding

\footnotetext{
${ }^{4}$ Consistent with this idea, several studies have provided evidence associating state insurance regulation with excessive compliance costs, cost inefficiencies and duplication of efforts (Grace and Klein, 2000; Klein and Schacht, 2001; Grace and Phillips, 2007).

${ }^{5}$ The extent to which these initiatives have achieved real reform, and whether they are sufficient to eliminate efficiency gains from federal chartering and regulation, remain subject to debate (Harrington, 2006). However, it is clear that in principle such coordination may improve regulatory efficiency.
} 
insurers or insurance transactions. In these cases, providing the service at a more centralized level of government may not yield the efficiency gains that could arise with centralization of ex-ante or preventive regulatory functions. Indeed, inefficiencies may be created if centralized responses are slower and less tailored to specific circumstances. Consumers' cost of access when dealing with a centralized level of government may also be higher.

There may be some aspects of consumer complaint handling that could benefit from cooperation or centralization. In recent years, the NAIC has tried to improve and standardize complaint handling, producing a white paper to identify best-practices in this function (NAIC, 2000). The NAIC has also created a national consumer complaint database that allows consumers' to access information about companies' complaint experience in all states and lines rather than only at the state level. These are important examples of how certain aspects of complaint handling may improve through interstate coordination or centralization.

A very different kind of consideration is the political economy at each level of government. Some argue that state regulators will be more susceptible to rent-seeking than federal regulators, leading to distortions in regulatory outcomes. In this view, social welfare may be enhanced by a change in the regulatory venue if institutions cannot be reformed. A number of studies suggest that state insurance regulation is affected by interest group pressure (Meier, 1988; Cummins, Phillips and Tennyson, 2001), but studies of federal agencies suggest they may be susceptible to similar pressures. ${ }^{6}$

\footnotetext{
${ }^{6}$ There is relatively little literature comparing state and federal agencies in this regard, but some evidence suggests that states may be more susceptible to political influence (e.g., Koontz, 1997).
} 
Moreover, the existence of interest group influence is not proof that regulations are inefficient (Noll, 1989).

Objections to the OFC specifically, as opposed to the general idea of federal regulation, have often centered on the political influence that may be created if firms are allowed to choose their regulator. Some observers applaud this idea because it would create competition between regulators, which should lead to more efficient regulations. Others argue that a dual system will increase regulator susceptibility to industry rentseeking, leading to a 'race to the bottom' as regards consumer protection. Indeed, some have argued that the threat of an OFC has already reduced consumer protection as state regulators attempt to stave off industry pressures for federal regulation (Hunter, 2003).

From a political economy perspective it is not clear that regulatory competition will lead to a 'race to the bottom'. Regulators receive political pressure from consumers as well as from industry, and this could lead to higher levels of consumer protection. ${ }^{7}$ The dual U.S. bank regulation system has clearly not led to de minimus regulation, since federal and state laws contain a number of significant consumer protections (Bair, 2003) and U.S. regulation is more stringent than in many other countries (Jackson, 2007). That said, federal bank regulators have been noted to weight solvency regulation more heavily than market conduct regulation, and relaxed regulatory oversight of mortgage terms and disclosures may have contributed to the recent mortgage crisis.

\section{Regulatory Competition and Consumer Protection}

Two primary concerns have been raised about federal insurance regulation and consumer protection: (1) that federal regulators will naturally be less focused on

\footnotetext{
${ }^{7}$ For example, Potoski (2001) argues that consumer pressures lead to state environmental protection standards that are higher than federal standards in many cases.
} 
consumer protection and (2) that a dual regulatory system (or the threat of one) will reduce all regulators' focus on consumer protection. I examine consumer protection regulation by state insurance departments to provide some indications of whether these concerns have merit. To explore whether pressure for an OFC has reduced states' focus on consumer protection, I analyze trends in consumer protection regulation over time. To explore whether federal regulation might be less focused on consumer protection than state regulation, I compare state insurance regulation to federal and state bank regulation.

\section{$\underline{\text { Trends in State Consumer Protection }}$}

Consumer protection regulation in state insurance departments falls largely into two functional areas: market conduct regulation - performing market conduct exams and assuring that insurance producers are dealing with consumers in a fair and consistent manner; and consumer services - answering consumer questions and looking into complaints about insurers and producers (NAIC, 2006). State resources devoted to these functions can be measured using budgets, regulatory staffing levels, and the number of exams, regulatory actions or other services provided. To provide evidence on regulatory resource changes over time, I compare aggregate data for the year 2006 to comparable data for earlier years. All data are taken from volumes of the NAIC's State Insurance Department Resources Report. Budget data are not provided by regulatory function, so staffing and activity levels are used to analyze trends in regulation.

There is no doubt that the resources states devote to insurance regulation have grown enormously over time. In combination, the states budgeted $\$ 605.1$ million for insurance departments in 1994 and this grew to $\$ 1,199.7$ million by 2006. After accounting for inflation this amounts to a 45.8 percent real increase in insurance 
department budgets over the period. ${ }^{8}$ Nonetheless, the size of the insurance market has also increased over the same period, growing from premium volume of $\$ 695.8$ billion in 1994 to $\$ 1,408$ billion in 2006. As a percentage of premium volume, insurance department budgets have remained relatively constant over time. In each year from 1994 to 2006 , total budgets ranged from 0.08 percent to 0.10 percent of total premiums. Relative budget size trended upward in the mid-1990s, peaking at 0.10 percent of premiums in 1997; budgets have trended downward since then, and the 2006 budget to premium ratio of 0.085 percent is about the same as in the early 1990s.

Aggregate regulatory staffing levels have also grown over time. In 1994 the states employed 9,729 full-time-equivalent (FTE) staff, and in 2006 they employed 13,632 FTE staff. ${ }^{9}$ This represents a 40.1 percent increase over the time period. However, when compared with the real increase in budgets (45.8 percent) or the real increase in insurance premiums (48.7 percent), insurance department staffing has declined in relative terms.

In the area of market conduct regulation the states employed a total of 620 FTE staff in 2006, which represents 4.5 percent of total departmental staff. In the same year states employed 1,174 FTEs in the consumer affairs area, which represents 12.7 percent of total staffing. Due to changes in the NAIC reports format, no comparable data are available for the 1990s. However, in 2003 staffing in market conduct regulation was 660.1 FTEs and in consumer affairs it was 1563.9 FTEs, or 6.0 percent and 15.0 percent of total staffing, respectively. Thus, the relative effort devoted to these regulatory functions appears to have declined over time.

\footnotetext{
${ }^{8}$ All amounts in this paper are deflated using the Consumer Price Index.

${ }^{9}$ These figures exclude contractual employees.
} 
Examining trends in staffing levels by position tells a slightly different story, however. Comparing 2003 and 2006 data, staffing of consumer affairs line functions (including complaint staff and consumer advocates) increased from 1082.75 FTEs to 1251.85 FTEs. Staffing of market conduct positions (examiners and analysts) increased from 419.0 FTEs to 436.75 FTEs. This represents a 15.5 percent increase in consumer affairs professionals and a 4.2 percent increase in market conduct professionals over the period. ${ }^{10}$

Although published data are not directly comparable over time, the NAIC reports data by position for the 1990s as well. Using data from 1994 we observe that the states employed 790.3 (FTE) complaint analysts and consumer advocates and 307.6 (FTE) market conduct examiners. The growth in staffing of these functions from 1994 to 2006 represents 58.4 percent increase in complaint handlers and a 42.0 percent increase in market conduct examiners. Compared with the 48.7 percent in real premium growth over this period, this represents a shift in resources toward complaint handling and away from market conduct examinations. Compared with the 41.0 percent increase in total staffing over the period, we see a similar but less dramatic shift in resources.

We can also compare regulatory activity levels over time. In 2006 the states undertook a total of 1,044 market conduct examinations, and 376 combined financial and market conduct examinations. By comparison, in 2003 states performed 1,261 market conduct exams and 387 combined exams. In 1998 states performed 1,083 market conduct exams and 749 combined exams; and in 1994 1,477 market conduct and 363 combined exams were carried out. When considering either the raw numbers or when

\footnotetext{
${ }^{10}$ I have excluded contractual staff under the view that they fill transitory staffing needs. If contractual staff are included we observe a 0.7 percent reduction in market conduct staffing between 2003 and 2006.
} 
normalizing by premium volume, the extent of examination activity has clearly declined over time. However, because the number of licensed insurers supervised by the states has declined over time, the number of exams per insurer may have remained more constant. The NAIC reports the number of domestic insurers as 7,929 in 1994, 8,123 in 1998, 7,685 in 2003 and 7,660 in 2006. Thus, even after this adjustment examination frequency declines slightly over time - from 0.23 per insurer in 1994 and 1998, to 0.21 per insurer in 2003 and 0.19 per insurer in 2006. Market conduct exams have also decreased over time as a proportion of total exams (where the total includes financial exams). In 1994, 61.2 percent of all exams included market conduct; this fell to 57.8 percent in 1998, 55.7 percent in 2003 and 52.5 percent in 2006.

One other trend in market conduct exams deserves mention: the increasing proportion of discretionary or targeted examinations. In 1994, only 44.1 percent of market conduct exams were discretionary, and this percentage was generally reflective of all years in the mid-1990s. However, discretionary exams accounted for 55.0 percent of market conduct exams in 1998, 63.8 percent in 2003 and 66.7 percent in 2006. Thus, the decline in market conduct exams appears to reflect a change in regulatory philosophy over time, with decreased emphasis on routine market conduct examinations (see Klein and Schacht, 2001).

As noted previously, state insurance departments rely heavily on ex-post complaint handling as a regulatory tool. In 2006 the states collectively received 392,482 complaints and 2,547,380 inquiries from consumers, for a total of 2,939,862 contacts. To facilitate consumer contacts and complaints, state insurance departments routinely provide toll-free telephone lines and online complaint services for consumers. The 
number of states providing these services has increased over time, with states adding online complaint capabilities in recent years and toll-free hotlines in earlier years. In 1994 only 28 states provided a toll-free hotline and online services were not available. In 2006, 45 states provided a toll-free consumer hotline and 39 states provided an online complaint form for consumers' use. As an additional service, 44 states report that they make aggregated complaint data available to the public, and 20 states make these complaint statistics available on their website.

Providing procedures and personnel to handle consumer inquiries and complaints can be viewed as an input to consumer protection regulation; but the volume of consumer complaints received may be more appropriately viewed as a regulatory outcome. Under this view, we would expect the volume of complaints to be inversely related to the stringency and effectiveness of ex-ante regulatory actions, with increased complaint handling substituting for reduced market conduct regulation. We have noted a decrease over time in regulatory resources devoted to market conduct examinations; do we see a corresponding increase in consumer complaints?

Overall, this does not appear to be the case. The number of consumer complaints per year has not changed dramatically over time. In 1994, 444,867 complaints were received and in 1998, 405,323; in 2003, 466,902 complaints were received; in 2006, complaints totaled 393,654. When normalized by real premiums, complaint volume demonstrates a steady downward trend over time; departments received 0.38 complaints per million dollars of premiums in 2006 compared with 0.64 in 1994, a 40.6 percent reduction. Normalizing instead by state population reveals a less steady downward trend (with 2003 showing an increase), but an overall reduction in complaint volume over the 
period. In 1994, insurance departments received 1.691 complaints per 1,000 residents, compared with 1.315 in 2006, a 22 percent reduction over the period.

There are two other complaint handling trends worthy of note. First, the relatively constant number of complaints combined with the increase in consumer affairs staffing levels over time means that the caseload of complaint personnel has declined. Complaints totaled 563 per FTE in 1994 and declined to 314 per FTE in 2006. Lower caseloads may provide shorter response times or more satisfactory responses for consumers (although no data are available on these outcomes).

The second notable trend is that the total number of consumer contacts (complaints and inquiries combined) has not increased over time. In fact, the number of non-grievance related inquiries has declined in recent years. Inquiries increased from 3.2 million in 1994 to 3.5 million in 1998, but trended down to 2.9 million in 2003 and 2.6 million in 2006. This suggests that consumers may be obtaining desired information through means other than direct contact with regulators (perhaps including online information provided by regulators).

\section{Comparing Insurance and Bank Regulation}

The U.S. banking industry operates under a dual state-federal system of chartering and regulation. State chartered banks are regulated by the states, with regulatory responsibilities shared by federal regulators through the Federal Deposit Insurance Corporation (FDIC) or the Federal Reserve Board (FRB). Federally chartered banks are regulated by the Office of the Comptroller of the Currency (OCC) and thrifts are regulated by the Office of Thrift Supervision (OTS), both within the Treasury 
Department. ${ }^{11}$ State bank regulators cooperate under the auspices of the Conference of State Banking Supervisors (CSBS).

Because of this dual structure comparing bank and insurance regulation is one approach to contemplating the potential implications of an OFC for insurance companies. Bair (2003) provides an extensive comparison of federal bank regulation and state insurance regulation. Her study concludes that there several important differences between consumer protection regulation in banking and insurance: (1) federal bank regulators devote more budget and staffing to market conduct examinations than do state insurance departments; (2) federal bank regulators conduct more market conduct examinations than state insurance regulators; (3) state insurance regulators rely more heavily on front-end regulation than federal bank regulators; (4) state insurance regulators receive far more (nine times as many in 2002) consumer complaints than federal bank regulators; (5) federal bank regulators devote fewer staff FTEs to handling complaints, and the caseload of federal complaint analysts was higher than that of their state insurance counterparts. These findings are less suggestive of less consumer protection by federal bank regulators than they are of a different focus of market conduct regulation in the two industries.

It is clear that federal bank regulators provide less in the way of consumer services than state insurance regulators. But, perhaps that is a role handled by state bank regulators. To compare consumer services in insurance and banking at the state level, state insurance and banking department websites were searched in fall 2007. The purpose in visiting insurance department websites was to validate states’ reports of online services, and to investigate how readily accessible those services are. These searches

\footnotetext{
${ }^{11}$ Federal credit unions are regulated by the National Credit Union Administration.
} 
confirmed that consumers have easy access to complaint filing in most states. The researchers were able to find information about how to file a complaint on the departmental websites of 49 of the states, and 35 states provide a link to complaint filing information directly on the homepage. Access to complaint statistics is not quite as good: researchers were able to locate complaint statistics for only 26 states, and in only 6 of those states was the link to complaint statistics available on the homepage.

Searches of state banking department websites revealed that state bank regulators provide consumers with poorer access to services than do their insurance counterparts. Fifty of the 51 (inclusive of DC) state banking departments provide information on their websites about filing a complaint, and 34 of these provide a link to that information on the department homepage. Forty one of the states also inform consumers about how to contact federal bank regulators. However, this information is generally provided in the form of cautioning the consumer to ascertain whether the state is the appropriate regulator before filing a complaint; with the consumer left to sort through a list of the regulatory agencies and the conditions governing which agency regulates the bank. In addition the vast majority of states require submission of a written complaint by mail or by fax. Only 18 states allow online filing of complaints and only 20 states offer a toll free phone line for consumers. Only one state makes summary data regarding bank complaints available on its website.

Data on complaint volume is difficult to obtain for the state bank regulators. Searches of the agency websites turned up only several instances in which complaint volume was mentioned in the department's annual report or in other agency documents. In fiscal year 2007, Maine’s Division of Banking reported receipt of 741 complaints. 
Washington’s 2006 Annual Report states that it received 1,095 complaints in 2005 and slightly fewer in 2002-2004. In Congressional testimony, New York's bank supervisor reports that the agency receives about 2,200 complaints per year (Neiman, 2007). These data suggest that the larger number of complaints in the insurance industry is not solely a function of insurance regulation occurring at the state level. State banking supervisors also receive many fewer complaints than state insurance regulators.

There are several other potential reasons for the much higher complaint volume in insurance than in banking. One possibility is the difference in focus of market conduct regulation among bank and insurance regulators. If market conduct exams reduce market conduct problems, fewer exams will be associated with more consumer complaints. We do not observe this trade-off between the number of market conduct exams and consumer complaint volume over time in the insurance industry, but it is still possible that on average there is an inverse relationship between exam intensity and complaint volume.

Another possibility is that higher complaint volume is linked to the greater access to complaining provided by insurance regulators. Although only a small fraction of consumer contacts to insurance departments involve a grievance (complaints constituted only 13.3 percent of consumer contacts to insurance departments in 2006), easier access is likely to increase the total number of contacts and thus to increase the number of complaints.

Another potential reason that insurance regulators receive more complaints than bank regulators are differences in the products offered. Insurance regulators in Kansas, Michigan, Wisconsin and Wyoming report statistics on the breakdown of complaints by insurance sector and the reasons for complaints. The data for 2006 reveal both 
similarities and differences across the states. In all four states, complaints are more prevalent in property-casualty insurance and accident-health insurance than in life and annuities. However, there are variations across the states in the relative prevalence of complaints by line; most notably, in two of the states, accident-health insurance accounts for well over 50 percent of claims, but these are substantially less prevalent in the other two states. With regard to reasons for complaints, in all four states the largest source of complaints is claims payments. In fact, claims-related complaints account for fully twothirds of complaints in Kansas, Wisconsin and Wyoming. In these states, the next most frequent source of complaints is customer service, with marketing/sales and underwriting grievances relatively less common. In Michigan, marketing and sales related complaints are much more prevalent.

In contrast, consider the OCC's statistics on complaints about banks for the period 2002-2006 (OCC, 2008). Credit cards accounted for 40 percent of complaints over this period; checking accounts for 26 percent of complaints; mortgages for 10 percent of complaints, and miscellaneous areas account for the remainder. Among credit cards, 51 percent of complaints surround disclosure of terms, 16 percent are regarding service and 14 percent are regarding debt collection issues. In checking, 42 percent of complaints are about poor customer service and 45 percent are about problems or disputes regarding transaction processing. Thus, overall, at least 20.4 percent of OCC complaints are related to disclosure issues, 17.3 percent to customer service, 11.7 percent to transactions problems and 5.6 percent to collection.

This comparison suggests that the relatively larger volume of consumer complaints in insurance may stem in part from the nature of the insurance transaction. 
Claims payments are a natural focal point of disagreements in insurance transactions, and consumers may have relatively poor understanding of the claim settlement process. Whether these disagreements represent a market conduct problem depends on a more precise understanding of the nature of the complaint and whether it is justified. A key piece of information not available in these data is the extent to which consumer complaints are justified. Neither the aggregate data reported in Insurance Department Resources Reports ${ }^{12}$ nor the data reported by the four states above indicate the percentage of complaints that are valid. This makes interpretation of the complaint generating process difficult.

Some data on this question are available from the state of Texas, which provides a detailed complaints database (the Internet Complaints Information System) on its website. ${ }^{13}$ Analysis of the Texas data for 2004 through 2006 shows that regulators found only about one-third of the complaints are justified. If results are comparable in other states, most consumer complaints are not an indicator of market conduct problems in the insurance industry. This finding adds credence to the argument that the large volume of consumer complaints is related to the complex nature of insurance transactions, and suggests that consumer misinformation may contribute to complaints.

A final possibility is that the dual structure of bank regulation may discourage consumer complaints, artificially reducing the number of complaints received by bank regulators. Because of the multitude of regulators, a consumer wishing to file a complaint against a bank may be uncertain with which agency to file it. As noted

\footnotetext{
${ }^{12}$ As noted previously the NAIC provides an online searchable database of complaints. However, the online search routine is not useful for research purposes and the NAIC does not make the database itself available.

${ }^{13}$ Downloadable databases and documentation are obtained from the Texas Department of Insurance website, found at http://www.tdi.state.tx.us/consumer/icis/index.html.
} 
previously, most of the state and federal bank regulators' websites list the relevant regulators and often provide links, but this information may create an inadvertent barrier to filing. Because the consumer is directed to determine which agency is responsible for their banking institution before filing a complaint, this added layer of complexity may discourage complaint filing.

There is substantial circumstantial evidence that the regulatory structure of the banking industry creates such problems for consumers. Several bank regulators note that they receive many complaints that should go to a different regulator. New York reported that nearly one half of the complaints it received in 2006 should have gone to federal regulators (Neiman, 2007) and Maine stated that nearly 60 percent of its complaints for fiscal year 2007 should have been made to federal regulators. Similarly, in 2006 the FDIC indicated that nearly one third of the complaints received were not within their jurisdiction. Further evidence of perceived problems is the fact that a bill recently introduced into the U.S. House of Representatives would require bank regulators to operate a single toll free hotline for all consumer complaints. In 2007, federal and state bank regulators also began a formal process of complaint sharing, and the CSBS reports that a majority of states have begun participating in the arrangement.

\section{Conclusions}

Based on a comparison of market conduct regulation and consumer complaints over time, it does not appear that the threat of regulatory competition has dramatically reduced consumer protection regulation by state insurance departments, if at all. Although resources devoted to market conduct regulation have fallen over time, and resources devoted to consumer complaint handling have concomitantly risen over time, 
these shifts appear to be the result of changes in regulatory philosophy rather than a rise in market conduct problems due to relaxed oversight. In fact, the volume of consumer complaints has been relatively constant over time and has decreased when measured in relation to market size. These trends and other available evidence tend to favor the conclusion that regulatory competition has spurred efficiency enhancing changes in state market conduct regulation, as economic theory would predict.

A comparison of consumer access provided by insurance and bank regulators suggests that state insurance regulators provide better complaint services than state and federal bank regulators. At the federal level this is largely due to the difficulties consumers may have in determining the appropriate bank regulator; at the state level it is also due to limited complaint services provided. Although it is not apparent that federal regulation alone limits consumer access, a dual system of state-federal regulation may do so. These patterns suggest that barriers to consumer complaint filing may arise with a dual system of state and federal regulation in the insurance industry. Given the far greater number of complaints received in insurance than in banking, the complications for consumers that may be created by a dual structure would be more significant.

These conclusions are consistent with the statements of some observers who have suggested that the most important advantage of state insurance regulation may be the greater responsiveness of state regulators in dealing with consumer complaints and providing other consumer services (Grace and Klein, 2000; Bair, 2003). However, questions remain regarding the value of these services and the appropriate level of service provision by the states. Data from all states show that insurance departments deal with a much larger number of consumer inquiries than consumer complaints, and data from one 
state (Texas) suggests that a large majority of complaints are unjustified and that only a very small fraction lead to regulatory enforcement actions. Although these patterns should hearten those concerned about market conduct problems in insurance markets, others might wonder if the services provided by the states could be better provided through other means. 


\section{References}

Bair, S., 2003. Consumer Ramifications of an Optional Federal Charter for Life Insurance. Isenberg School of Management, University of Massachusetts. http://www.isenberg.umass.edu/finopmgt/uploads/basicContentWidget/8631/baircons-ramifications.pdf.

Besley, T. and S. Coate, 2003. Centralized Versus Decentralized Provision of Local Public Goods: A Political Economy Approach. Journal of Public Economics 87: 2611-2637.

Cummins, J.D., R.D. Phillips and S. Tennyson, 2001. Regulation, Political Influence and the Price of Automobile Insurance. Journal of Insurance Regulation 20(1): 9-50.

Grace, M.F. and R.W. Klein, 2000. Efficiency Implications of Alternative Regulatory Structures, in P. Wallison, ed., Optional Federal Chartering and Regulation of Insurance Companies. Washington: AEI Press.

Grace, M.F. and R.D. Phillips, 2007. The Allocation of Governmental Regulatory Authority: Federalism and the Case of Insurance Regulation. The Journal of Risk and Insurance 74(1): 207-238.

Harrington, S.E., 2006. Federal Chartering of Insurance Companies: Options and Alternatives for Transforming Insurance Regulation. Networks Financial Institute Policy Brief 2006-PB-02.

Harrington, S.E., 1992, Rate Suppression, Journal of Risk and Insurance 59:185-202.

Hunter, R., 2003. Testimony of the Consumer Federation of America before the U.S. Senate Committee on Commerce, Science and Transportation. October 22. 
Jackson, H., 2007. Variation in the Intensity of Financial Regulation: Preliminary Evidence and Potential Implications. Yale Journal on Regulation 24(2): 253-291. Klein, R.W. and J. Schacht, 2001. An Assessment of Insurance Market Conduct Surveillance. Journal of Insurance Regulation 62: 263-404.

Koontz, T.M., 1997. Differences between State and Federal Public Forest Management: The Importance of Rules. Publius 27(1): 15-37.

Meier, K.J., 1988. The Political Economy of Regulation: The Case of Insurance. Albany: SUNY Press.

National Association of Insurance Commissioners, 2000. Consumer Complaints White Paper. Kansas City: NAIC.

National Association of Insurance Commissioners, 2006, 2004, 1998, 1994. Insurance Department Resources Report. Kansas City: NAIC.

Neiman, R.H., 2007. Testimony before the Financial Services Committee Subcommittee on Financial Institutions and Consumer Credit, December 12.

Noll, R., 1989. Economic Perspectives on the Politics of Regulation. In R. Schmalensee and R. Willig, eds., Handbook of Industrial Organization. Vol. II. New York: North-Holland.

Oates, W., 1972. Fiscal Federalism. New York: Harcourt Brace.

Potoski, M., 2001. Clean Air Federalism: Do States Race to the Bottom? Public Administration Review 61(3): 335-342.

Tennyson, S., 1999. Government Regulation of Insurer Sales Practice. Market and Public Organisation, University of Bristol, 2 (December): 7-10. 